\title{
Stuck in a Loop: Individual and System Barriers for Job Seekers With Disabilities
}

\author{
Jean P. Hall \\ Kathy Parker
}

\begin{abstract}
Research conducted within Temporary Assistance to Needy Families (Personal Responsibility and Work Opportunity Reconciliation Act of 1996) and Workforce Investment Act of 1998 systems indicates pervasive issues hindering program effectiveness for job seekers with disabilities. This population frequently experiences employment barriers beyond those of able-bodied job seekers, including significantly lower self-esteem. Service providers need and want information about disability but do not know how to obtain it. Program staff and job seekers with disabilities get stuck in a loop wherein each questions their ability and neither feels empowered to make meaningful changes to improve outcomes. Career counselors may need to expand their role to be more culturally relevant for these clients.
\end{abstract}

The ultimate goal for two of America's national public assistance programs, Temporary Assistance to Needy Families (TANF; Personal Responsibility and Work Opportunity Reconciliation Act of 1996) and the Workforce Investment Act of 1998 (WIA), is that their clients become more self-sufficient through employment. Weinrach (2003) recommended that career counselors expand their role beyond traditional notions of career development to include providing culturally relevant support to clients of these major employment programs. For example, a career counselor working in a WIA workforce center may encounter a client who needs life skills training and reading instruction more than he or she needs counseling or a single mother who needs a job at her current skill level with access to public transportation and affordable child care rather than counseling to learn a new set of skills (Weinrach, 2003).

Over the course of three studies, we investigated the ways in which the TANF (one study) and WIA (two studies) systems could better meet the needs of job seekers with disabilities; we observed a pattern of low selfesteem among consumers with disabilities and low disability awareness among service providers that, together, produced an often endless loop without results (i.e., employment). Thus, this article takes Weinrach's (2003) notion of culturally relevant support one step further by exploring how job seekers with disabilities interact with program staff in TANF and WIA workforce center settings and discussing the implications for career counselors.

Jean P. Hall and Kathy Parker, Center for Research on Learning, Division of Adult Studies, University of Kansas. This research was supported in part by grants from the National Institute on Disability and Rehabilitation Research (H133B000500), the Kansas Department of Social and Rehabilitation Services, and the Kansas Department of Human Resources. All studies reported in this article were approved by the University of Kansas Human Subjects Committee of the KU Center for Research. Correspondence concerning this article should be addressed to Jean P. Hall, Center for Research on Learning, Division of Adult Studies, University of Kansas, J. R. Pearson Hall, Room 517, 1122 West Campus Road, Lawrence, KS 66045-3101 (e-mail: jball@ku.edu).

(C) 2010 by the National Career Development Association. All rights reserved. 


\section{TANF and WIA Employment Programs}

Although neither TANF nor WIA services are specifically targeted to people with disabilities, people with disabilities disproportionately use or need to use them. In fact, a full $29 \%$ of TANF recipients have at least one physical or mental health impairment in contrast to $11 \%$ of a comparable non-TANF population (U.S. General Accounting Office [GAO], 2002). Furthermore, Americans with disabilities experience very high unemployment rates, estimated at about 63\% (Erickson \& Lee, 2008), and, thus, have a greater need for WIA employment services than do their counterparts without disabilities.

Not only are people with disabilities represented at higher rates in TANF and WIA programs, they also experience poorer outcomes. The TANF program, as created in the 1996 comprehensive welfare reform effort, imposes a 5-year lifetime limit for individuals to receive cash assistance. Furthermore, TANF requires recipients to be employed within 2 years of entering cash assistance, with very few exceptions. The emphasis is "work first," with limited opportunities for educational or rehabilitation services. The GAO (2002) found that recipients with impairments were half as likely to exit welfare rolls as those without impairments.

WIA was enacted with the goal of consolidating a variety of federal job service programs with universal access as one of its main principles. This legislation was operationalized, in part, through the creation of the One-Stop service delivery system in which any job seeker should be able to access a series of core services at one location. However, several studies have indicated that the One-Stop centers have often been ineffective in providing adequate access and services to job seekers with disabilities (National Council on Disability, 2002; Storen, Dixon, \& Funaro, 2002; Timmons, Schuster, Hamner, \& Bose, 2001; U.S. Department of Labor [DOL], 2002). In fact, the majority of One-Stop managers who responded to a national survey on this subject recognized that their staffs needed additional training on career counseling for job seekers with disabilities (Storen et al., 2002). In another study, consumers of employment services recommended that such generic services as One-Stop centers and the welfare system should improve the range of supports available to individuals with disabilities seeking employment (Timmons et al., 2001). Overall, these studies have focused primarily on programmatic and physical access rather than on interactions between staff and consumers.

Job seekers with disabilities face external obstacles to employment (e.g., physical limitations, gaps in employment due to illness, need for accommodations) that counselors can help them address. However, job seekers with disabilities also face overarching, intrinsic employment barriers beyond those of job seekers without disabilities, including low self-esteem and self-confidence-obstacles that the TANF and WIA One-Stop systems may exacerbate and for which counselors must also be prepared to address. For example, Joiner, Lovett, and Goodwin (1989) found that people with disabilities are less assertive than persons without disabilities and may be less able to advocate for themselves. Furthermore, Bandura (1997) noted persons may question their self-worth, despite being very competent, if they are members of groups that are not valued by society, such as people with disabilities.

Our three studies were designed to investigate the job-seeking experiences of people with disabilities in TANF and WIA systems and to better 
understand reasons for limited success of universally accessible public assistance and employment programs for this population. By identifying and increasing awareness of barriers and addressing knowledge gaps, we hope to strengthen the capacity of counselors in these systems to more effectively provide employment support and services to people with disabilities.

\section{TANF Study}

\section{Method}

In this state-funded project, designed to increase the employment of TANF recipients with disabilities (Mellard \& Hall, 2001), we conducted six focus groups and administered a survey to 57 TANF recipients. Our purpose was to better understand their experiences in the welfare system, their beliefs about work, their quality of life, their ideas about ways to improve the system, and other issues related to successfully leaving public assistance. We elected to use focus groups rather than participant observation or individual interviews because of the inherent difficulty of observing the long-term process of job seeking, the anticipated insights into this complex behavior from having participants compare their experiences and beliefs, and the potential for synergistic idea generation that can be fostered by a focus group setting (Morgan, 1997).

\section{Participants}

TANF recipients with and without disabilities in both urban and rural communities participated in the study. Case managers referred TANF clients to the study, and each client who participated received $\$ 50$. Participants were $81 \%$ women. Participants' self-reported race/ethnicity was $63 \%$ White; 26\% African American; 2\% each of Native American, Hispanic, and Asian; and 5\% other. Thirty participants (53\%) reported no disability, and 27 participants (47\%) indicated they experienced one or more disabilities. Of participants, including co-occurrences of disabilities, $32 \%$ reported a physical disability (e.g., impaired vision or hearing, carpal tunnel syndrome, herniated disk), 25\% reported a cognitive disability (e.g., learning, mental retardation), 19\% reported a health condition (e.g., diabetes, emphysema, asthma), and 19\% reported a mental/emotional condition (e.g., depression, anxiety, bipolar disorder).

\section{Survey Instrument}

Research staff (the authors and other colleagues) designed a quality of life survey to assess physical and material well-being, performance of adult roles, and sense of personal fulfillment of respondents based on quality of life outcomes articulated by Halpern (1993). The survey instrument included several items that evaluated individual global self-esteem taken from the Rosenberg Self-Esteem Scale (RSE; Rosenberg, 1979) or validated variations of the RSE items (Marsh, 1994; National Opinion Research Center, 1988). Participants responded to this instrument using a 4-point Likert-type scale, with $1=$ disagree strongly and 4 = agree strongly.

Post hoc analysis corroborated the recurrent theme of global self-esteem, which may influence social interactions (Robins, Hendin, \& Trzesniewski, 2001). Thus, survey items that address global self-esteem-that is, the "esteem in which one holds one's overall self-image" (Rubin \& 
Hewstone, 1998, p. 42)-are of interest in this discussion. Robins et al. (2001) found construct validation for a single-item measure of an adult's self-esteem, such as the items in the RSE. Through item-response theory analysis, Gray-Little, Williams, and Hancock (1997) found that the RSE provides a highly reliable and internally consistent measure of global self-esteem and that the uniformity of the item content and strong discrimination parameters of the 10 items allow for a shortened survey without compromising the measurement of global self-esteem.

\section{Procedure}

We met with participants in local social services offices. Each participant first signed a consent form and then completed the Quality of Life Survey, with assistance if needed. Following these paper-and-pencil tasks, two or three project staff members led nondirective focus group discussions using a structured topic guide and open-ended questions (Debus, 1988; Krueger \& Casey, 2000) about such general topics as impediments to exiting the system, unmet service needs, attitudinal issues, and educational needs. Each session lasted no more than 2 hours.

\section{Data Analysis}

Research staff performed both quantitative and qualitative analyses. They tabulated survey results and performed an analysis of variance to ascertain whether participants with disabilities varied significantly from those without disabilities on the various measures. In analyzing the focus group data, two researchers (the authors) compared notes and transcripts from each focus group session for reliability and to identify the "big ideas" from the sessions. Next, working individually, each researcher unitized the data by highlighting information units (e.g., words, phrases, and passages) in the notes and transcripts. Each then margin coded the transcripts to categorize the units, followed by tabulation of the categories (Vaughn, Schumm, \& Sinagub, 1996). Finally, the two researchers worked together to negotiate and compare categories between focus group sessions with the goal of identifying recurring themes or pattern-matching (Yin, 1994).

\section{Findings}

A dominant theme that emerged from the discussions was that participation in welfare is depressing and erodes one's self-esteem. Participants made the following comments: "It's your self-esteem I know has got a lot to do with it because being on [TANF assistance] does not make you happy with yourself or anything else" and "Mr. [X] did not treat me like I was an individual .... He treated me like I was substandard, and my self-esteem was a real problem."

Some participants said they felt marginalized in many social contexts, including church-"church is for rich people" — and at their children's schools- "because we're poor." Feelings of embarrassment when using food stamp cards to buy groceries or standing in line at the welfare agency were prevalent, which were illustrated by the following comments:

- I hang my head if I use my [food stamp] card . . . I think people look down on you. That's the way I used to be.

- It's embarrassing. I go out of town to shop. 
- I don't want to be here standing in line waiting for a handout. It's embarrassing, and Lord help you if you see somebody you know.

- It doesn't matter how many times I've been to the grocery store and you get in that line and pull out that card, and the people behind you start whispering. You're mad . . . It's embarrassing. . . . You want to say that you don't care what they think, but deep down inside, you do care what they think.

- I feel so embarrassed to use any kind of thing that has to do with [public assistance], anything. It's just, like, putting a characterization on me that I'm not ... [voice trails off].

Although participants, both with and without disabilities, verbally expressed such perceptions of social status and self-worth, participants with disabilities scored lower on every survey item that addressed self-esteem than did participants without disabilities. Specifically, persons with disabilities scored significantly lower, and with moderate to large effect size (Cohen, 1988), on responses to two items measuring self-esteem. For the item "I feel good about myself," $F(1,55)=4.34, p=.042, \eta^{2}=.073$. For the item "I am able to do things as well as most other people," $F(1,54)=$ $11.38, p=.001, \eta^{2}=.174$. The implication of these lower scores is that, even among a small sample of people who could reasonably be expected to have low self-esteem, membership in the disability group accounts for variance in self-esteem over and above other factors related to receiving welfare benefits (e.g., poverty, stigma, lower social status).

\section{WIA Studies}

\section{Method}

We conducted two studies using similar methods and procedures in different locations and at different points in time; for this article, we have combined the data and findings. The overall purpose of these studies was to increase the responsiveness of the One-Stop system to job seekers with disabilities. We elected to use consumer and provider focus groups rather than individual interviews or participant observations for the same reasons expressed in the synopsis of our TANF study. However, we supplemented focus group findings with data collected from authentic visits to One-Stops made by job seekers with disabilities, referred to as "mystery customers" (DOL, 2007b).

\section{Participants}

Thirty-one One-Stop staff members from six communities (five urban and one rural) participated in staff focus groups. At three locations, all One-Stop staff members and partnering agency staff members participated in focus group sessions; at the other three locations, One-Stop managers selected staff representatives who they believed knew the most about working with job seekers with disabilities to participate.

Staff members from centers for independent living, transition specialists, vocational rehabilitation agencies, mental health clinics, and support groups in six communities recruited 48 focus group participants $(65 \%$ women), using disability and current job-seeking status as selection criteria. To create an environment that encouraged open communication, we opted not to have participants fill out demographic surveys. Requiring self-identification of disabilities reinforces a "medical model" of disability, 
which many in the disability community, especially those individuals in the independent living movement, profoundly distrust (Kirschner, 2006; Szymanski \& Trueba, 1994). However, from participant comments, we ascertained that a range of disability types was represented, including people with physical, cognitive, emotional, and medical disabilities.

The 8 mystery customers were active job seekers with disabilities recruited with the help of the same organizations noted earlier. The mystery customers were paid $\$ 75$ to make two visits to a One-Stop center and evaluate their experiences. Like the participants in the consumer focus groups, all of the mystery customers were job seekers with disabilities. Four of the mystery customers had disabilities that were evident: 1 had multiple sclerosis and walked with a "limp"; 1 had cerebral palsy, with gait, cognitive, and communication difficulties; 1 had low vision; and 1 was blind. The other 4 had disabilities that were not apparent: 1 had asthma and depression, 1 had bipolar disorder, 1 had major depression, and 1 had recently been diagnosed with attention-deficit/hyperactivity disorder.

\section{Procedure}

As research staff, we probed the One-Stop staff focus-group participants to gauge their comfort levels in working with customers who have disabilities and their perceptions of training needs. We used a nondirective focus group format with a structured topic guide of open-ended questions (Debus, 1988) based on prior research (Hoff, 2001). The topics were (a) accessibility and auxiliary aids and services available in One-Stops; (b) how to make centers more inviting, welcoming, and inclusive of persons with disabilities; (c) how to communicate with a person about his or her disability; and (d) the rights and responsibilities of job seekers with disabilities.

Using the same focus group protocol, we led consumer focus groups in discussions about previous experiences with One-Stop or other employment service centers and ideas for more responsive services. The specific topics were (a) past and current job search activities; (b) how to make centers seem inviting, welcoming, and inclusive of persons with disabilities; (c) sharing information about their disability; and (d) the support services they would like in order to reach their employment goals.

Before any project activities, the local area One-Stop directors agreed to the use of a mystery customer evaluation method, which is also used by the DOL (2007b) to evaluate participant satisfaction with assistance received at One-Stop centers. Project staff met individually with mystery customers to obtain signed consent forms and acquaint them with the evaluation form. This form was based in part on a checklist created by the Institute for Community Inclusion (Hoff, 2001) that was designed for One-Stop center staff to evaluate the accessibility of their services to people with disabilities. We shortened the checklist and added questions to probe participants about their interactions with staff and their overall comfort levels in the One-Stop centers.

Each mystery customer made two trips to One-Stops. On the first visit, the mystery customers were to simply state they were looking for work, and, on the second visit, they were to say the standard online job search method was not working for them and ask if any other services were provided by the center. Mystery customers visited the One-Stop centers at the location and times that naturally fit their lifestyles. After each visit, they contacted the research staff to report their findings. 


\section{Data Analysis}

As with our TANF study, we used the same procedures to identify recurring themes from the focus group sessions (Vaughn et al., 1996; Yin, 1994). Mystery customer reports were analyzed in the same manner.

\section{Findings-Staff Focus Groups}

Issues related to training needs that emerged in the staff focus groups included how to feel more comfortable communicating with a person about his or her disability and the need for more information about other programs/resources available to individuals with disabilities. Consumer focus-group discussions corroborated these needs from the consumers' perspectives.

\section{Findings-Consumer Focus Groups}

As with the TANF study, we did not set out to specifically examine issues of self-esteem among consumers with disabilities; nonetheless, the issue emerged. Consumer focus-group participants stated that staff attitudes and interactions were important issues. One individual related a past experience at a One-Stop. She said, "I felt like [the staff person] was looking down on me like, 'What's wrong with her? She has all these computer skills, why can't she go out and get a job?"' Many participants voiced similar underlying and irresolvable doubts about how staff members treated them; l person said it was always in the back of his mind "that I'm walking in with a cane or a brace or walking in limping; are they putting me off because I'm disabled or are they really busy?"

The overall general perception seemed to be that One-Stop staff members and other job service providers do not understand barriers to employment for people with disabilities and are generally not comfortable working with people who have disabilities. This perception was corroborated by some One-Stop managers, who stated that members of their staff were so "nervous or afraid of doing something wrong" they come across as being inconsiderate to people with disabilities.

"I really do feel that I need a special kind of guidance just to get back into the workforce" was the sentiment of 1 consumer focus-group participant. With regard to disability-specific programs, consumers believed One-Stop staff did not understand or want to deal with the complexities involved (e.g., disability cash programs and health care assistance programs such as Social Security and Medicaid). As I participant observed, if customers with disabilities are always referred elsewhere, “you don't have a one-stop, you have two-stops. If everybody [i.e., the staff] had some disability training, that would definitely make it one-stop."

\section{Findings-Mystery Customer Evaluations}

Mystery customer reports also indicated that center staff members were not very helpful. This finding is due in part to the fact that most of this state's One-Stop centers use a "library model" through which customers are expected to direct their own job searches with minimal staff support. The mystery customers with disabilities, however, believed that they needed more services and support to find jobs than did people without disabilities and did not believe that those services were available at the One-Stop center they visited. Moreover, the majority of customers were 
reluctant to force the issue and ask for more intensive support. In fact, most said that they would not have gone back to the centers had we not specifically asked them to make a second visit.

Although we did not formally measure self-esteem of mystery customers, analyses of comments identified an underlying theme perhaps related to the interplay between staff attitudes and consumer self-esteem. Some mystery customers said, for example,

- I felt like [the staff person was thinking], "What do you want, and let me help you get online, and good-bye." The second time I just felt like I was bothering the guy.

- I got the feeling that [the staff person] wanted to come and get rid of me.

- I think [the staff person] was afraid to talk too much about my disability. Well, some people believe they're going to hurt your feelings.

\section{Discussion}

We found that people with disabilities face unique barriers in their job-seeking efforts and that service providers in the TANF and WIA systems often are not well prepared to provide appropriate services or supports to them. Findings from our three projects across service systems and disability types indicate self-esteem is an ongoing and pervasive issue for people with disabilities who are looking for work. Although lower self-esteem is associated with unemployment, even among people without disabilities (Turner \& Turner, 2004), our work suggests that it is more pronounced in job seekers with disabilities and may create a disproportionately larger barrier to finding employment for this population. Bernichon, Cook, and Brown (2003) found that people with low self-esteem who receive negative interpersonal feedback - even if only perceived as such — are likely to feel bad about themselves and show no desire to interact with a person who evaluates them negatively. Such a response is illustrated in our mystery customers' reluctance to return to the One-Stop centers after perceived negative interactions during their first visits.

In addition, our studies found service providers in these systems often believe they do not have sufficient information or resources to provide appropriate services to job seekers with disabilities. Johnson, Mellard, and Krieshok (2007) found that One-Stop staff members' self-efficacy in serving job seekers with disabilities could be modestly increased through training. Johnson et al. (2007) suggested other catalysts and sustainers of change in interactions between consumers and staff, such as

\footnotetext{
making prior knowledge of disability issues a hiring criterion, requiring more than a high school diploma, changing staff roles from that of "librarian" to that of "navigator," having supervisory staff communicate and model a moral imperative regarding services directed toward persons with disabilities, making structural changes toward accountability systems and external rewards, and implementing an overall customer service orientation. (p. 34)
}

Until such practices are the norm, Wright's (1983) observation will remain true: "Inconsistency of social attitudes brings about situations of psychological uncertainty for the person with a disability regarding how he or she will be received" (p. 29). Our work indicates that this uncertainty for people with disabilities is particularly pronounced in 
service settings, where they are seen as needy and where providers often feel uncomfortable in working with them.

Individually, issues of low consumer self-esteem or low staff knowledge and comfort levels can affect the ability of the TANF and One-Stop systems to successfully help move people with disabilities into employment. In combination, these issues present serious challenges to both customers of and providers in systems that are mandated to provide services to a broad range of people with varying needs. TANF and One-Stop staff members cannot be reasonably expected to become experts on working with people who have disabilities, in addition to their other responsibilities, and people with disabilities cannot simply overcome their personal barriers and needs because the system has difficulty accommodating them. Such a situation results in a vicious circle, or loop, wherein customers and staff members each question their own self-efficacy and neither feels empowered to make meaningful changes to effect better outcomes. On the other hand, if customers feel supported and staff members feel capable of responding to customers' needs, the dynamic can shift.

\section{Implications for Career Counselors}

Because career counseling is a core service under WIA legislation and is a service element to be included in Welfare-to-Work plans, counselors have the opportunity to address these issues as they work with job seekers who have disabilities. In the context of this study, culturally relevant services recommended by Weinrach (2003) for the welfare population must expand to include those that directly address disability and the accompanying challenges for both customer and provider. Having said this, we do not advocate a more clinical approach to providing services to people with disabilities. Indeed, Lee (2003) discussed the pitfalls of overemphasis on disabilities to the exclusion of considering individuals holistically and not as a condition to be treated. Rather, we hope to build an awareness of the duality of issues that may hinder the efforts of TANF or WIA staff members and counselors to provide appropriate services and to successfully help place clients with disabilities into employment.

The National Center on Workforce and Disability (2002) guidelines for serving people with disabilities include many practical and easily implemented suggestions for counselors-several of which may have a positive effect on consumer self-esteem. For example, counselors might adopt a universal approach to their interactions with consumers that would positively affect confidence when consumers with disabilities are treated the same as other job seekers (e.g., offering assistance to anyone filling out an intake form, not just people who look like they need help). Counselors can emphasize job seekers' abilities, rather than disabilities, and help them figure out how to market their skills and talents to employers. Likewise, counselors can avoid stereotypes about people with disabilities by not automatically steering them to such disability-only services as vocational rehabilitation, thus, potentially eroding a job seeker's self-esteem without adding any job-search benefits.

At the same time, career counselors can be attentive to the unique barriers to employment that people with disabilities may experience. For example, they can make it easier for people with disabilities to ask for and obtain auxiliary aids and services or other modifications by clearly indicating their availability verbally and in written materials. In 
particular, our findings suggest that counselors should be prepared to apply their self-esteem-related counseling skills when working with the population of job seekers with disabilities.

\section{Limitations}

These three studies were limited to job seekers with disabilities in a single state. However, TANF and WIA One-Stop centers are federal programs administered by states under specific guidelines, with the same reporting and service requirements nationally. The relatively small sample sizes in our study may limit the generalizability of our findings, but we believe they provide a strong foundation for future research.

\section{Future Research}

We anticipate that our findings will provide the impetus for more research into the interpersonal and social barriers to a productive employment counseling relationship in any setting with job seekers who have disabilities. However, this study observed but did not fully explore why job seekers with disabilities experience lower self-esteem compared with other job seekers. Also of interest may be the difference between subpopulations of people with disability (e.g., those people with congenital disability vs. those with acquired or adult-onset disability). Finally, we acknowledge that the DOL is aware of and working to address programmatic issues with One-Stop services to job seekers with disabilities (e.g., Disability Program Navigator Initiative [DOL, 2007a]); perhaps, after these programmatic changes have been widely implemented, a replication of our study would have merit.

\section{References}

Bandura, A. (1997). Self-efficacy: The exercise of control. New York, NY: Freeman.

Bernichon, T., Cook, K., \& Brown, J. (2003). Seeking self-evaluative feedback: The interactive role of global self-esteem and specific self-view. Journal of Personality and Social Psychology, 84, 194-204.

Cohen, J. (1988). Statistical power analysis for the behavioral sciences. Hillsdale, NJ: Erlbaum.

Debus, M. (1988). Methodological review: A handbook for excellence in focus group research. Washington, DC: Academy for Educational Development.

Erickson, W., \& Lee, C. (2008). 2007 disability status report: United States. Ithaca, NY: Cornell University Rehabilitation Training Center on Disability Demographics and Statistics.

Gray-Little, B., Williams, V., \& Hancock, T. (1997). An item response theory analysis of the Rosenberg Self-Esteem Scale. Personality and Social Psychology Bulletin, 23, 443-449.

Halpern, A. (1993). Quality of life as a conceptual framework for evaluating transition outcomes. Exceptional Children, 59, 486-498.

Hoff, D. (2001). Access for all: A resource manual for meeting the needs of One-Stop customers with disabilities. Boston, MA: Institute for Community Inclusion.

Johnson, D. R., Mellard, D., \& Krieshok, T. (2007). Raising disability awareness and self-efficacy of One-Stop workforce center staff serving job seekers with disabilities. The Review of Disability Studies: An International Journal, 3, 24-36.

Joiner, J., Lovett, P., \& Goodwin, K. (1989). Positive assertion and acceptance among persons with disabilities. The Journal of Rehabilitation, 55, 22-30.

Kirschner, K. (2006). Unequal stakeholders: "For you, it's an academic exercise; for me, it's my life." American Journal of Bioethics, 6, 30-32.

Krueger, R., \& Casey, M. (2000). Focus groups: A practical guide for applied research (3rd ed.). Thousand Oaks, CA: Sage.

The Career Development Quarterly 
Lee, R. (2003). Serving the "hard-to-serve": The use of clinical knowledge in welfare reform. Journal of Sociology and Social Welfare, 30, 59-78.

Marsh, H. (1994). Using the National Longitudinal Study of 1988 to evaluate theoretical models of self-concept: The self-description questionnaire. Journal of Educational Psychology, 86, 439-456.

Mellard, D., \& Hall, J. (2001). Responding to specific learning disabilities in Welfare-toWork clients and in the employment setting: Project final report. Lawrence: University of Kansas, Center for Research on Learning, Division of Adult Studies.

Morgan, D. L. (1997). Qualitative research methods series: Vol. 16. Focus groups as qualitative research (2nd ed.). Thousand Oaks, CA: Sage.

National Center on Workforce and Disability. (2002). OneStops.info briefs, 1. Retrieved from http://www.onestops.info/article.php?article_id=69\&subcat_id=61\#intro

National Council on Disability. (2002). National disability policy: A policy report. Washington, DC: Author.

National Opinion Research Center. (1988). National Educational Longitudinal Study of 1988: First follow-up student questionnaire (Office of Management and Budget No. 1850-0593). Washington, DC: U.S. Department of Education, National Center for Education Statistics.

Personal Responsibility and Work Opportunity Reconciliation Act of 1996, P. L. No. 104-193, 110 Stat. 2110 (1996).

Robins, R., Hendin, H., \& Trzesniewski, K. (2001). Measuring global self-esteem: Construct validation of a single-item measure and the Rosenberg Self-Esteem Scale. Personality and Social Psychology Bulletin, 27, 151-161.

Rosenberg, M. (1979). Conceiving of the self. New York, NY: Basic Books.

Rubin, M., \& Hewstone, M. (1998). Social identity theory's self-esteem hypothesis: A review and some suggestions for clarification. Personality and Social Psychology Bulletin, 2, 40-62.

Storen, D., Dixon, K., \& Funaro, A. (2002). One-Stop accessibility: A nationwide survey of One-Stop centers on services for people with disabilities. New Brunswick: The State University of New Jersey, John J. Heldrich Center for Workforce Development at Rutgers.

Szymanski, E., \& Trueba, H. (1994). Castification of people with disabilities: Potential disempowering aspects of classification in disability services. Journal of Rehabilitation, 60, 12-20.

Timmons, J., Schuster, J., Hamner, D., \& Bose, J. (2001). Characteristics of effective employment services: The consumers' perspective. Boston, MA: Institute for Community Inclusion/University Affiliated Program.

Turner, J., \& Turner, R. (2004). Physical disabilities, unemployment, and mental health. Rehabilitation Psychology, 49, 241-249.

U.S. Department of Labor. (2002). Summary report on the WIA reauthorization public forums. Retrieved from http://www.workforceatm.org/articles/printer_friendly. cfm?results_art_filename $=$ dolwiareaexecsum.htm

U.S. Department of Labor. (2007a). Disability program "navigator" initiative. Retrieved from http://www.doleta.gov/disability/onepagers/dpn_factsheet_april2007.pdf

U.S. Department of Labor. (2007b). DOL annual report, fiscal year 2005. Retrieved from http://www.dol.gov/_sec/media/reports/annual2005/annualreport.pdf

U.S. General Accounting Office. (2002). Workforce Investment Act: Coordination of TANF services through One-Stops has increased despite challenges (GAO-02-739T). Washington, DC: Author.

Vaughn, S., Schumm, J., \& Sinagub, J. (1996). Focus group interviews in education and psychology. Thousand Oaks, CA: Sage.

Weinrach, S. (2003). A person-centered perspective to Welfare-to-Work services: In pursuit of the elusive and the unattainable. The Career Development Quarterly, 52, 153-161.

Workforce Investment Act of 1998, Pub. L. No. 105-220, 112 Stat. 936 (1998).

Wright, B. A. (1983). Physical disability-A psychosocial approach (2nd ed.). New York, NY: Harper \& Row.

Yin, R. (1994). Case study research: Design and methods (2nd ed.). Thousand Oaks, CA: Sage. 